\title{
Challenges in intra-family donation
}

\author{
Vayena, Effy ; Golombok, Susan
}

DOI: https://doi.org/10.1017/CBO9781139026390.010

Posted at the Zurich Open Repository and Archive, University of Zurich

ZORA URL: https://doi.org/10.5167/uzh-63927

Book Section

Published Version

Originally published at:

Vayena, Effy; Golombok, Susan (2012). Challenges in intra-family donation. In: Richards, Martin; Pennings, Guido; Appleby, John B. Reproductive Donation : Practice, Policy, and Bioethics. Cambridge: Cambridge University Press, 168-188.

DOI: https://doi.org/10.1017/CBO9781139026390.010 


\section{Effy Vayena and Susan Golombok}

\section{Definition and prevalence}

Intra-family donation is gamete donation between family members of various degrees of blood or kin relationship. Most intra-family donation involves intra-generational donation between siblings or cousins, most commonly egg donation between sisters or sisters-in-law. Less frequently there is intergenerational donation: usually father to son, daughter to mother or niece to aunt.

There is little data on the prevalence of intra-family donation. Surveys conducted in North America report only the types of intra-family donation that are accepted in the participating centres but provide no information on the number of requests or actual procedures performed (Marshall, 2002; ASRM Ethics Committee Report, 2003). Similarly, the International Committee on Monitoring Assisted Reproductive Technologies (ICMART), which collects data from national IVF registers, does not collect data on specific types of donation. In the early days of IVF egg donors tended to be known. Some US fertility experts advocated sister-to-sister donation rather than anonymous donation (Lessor, 1993). Studies at that time reported positive attitudes towards egg donation by sisters among infertile couples (Sauer, 1988) and the broader public (Lessor, et al., 1990).

Today, most donations involve unknown donors. However, there appears to have been a recent rise in the use of known donors, including family members, in the UK and elsewhere. A study from Canada of the emotional and psychological impact of altruistic donation on known egg donors reported that 39 per cent of respondents had donated to a sister or cousin (Yee et al., 2007). There is also anecdotal information that UK fertility clinics have recently experienced an increase in requests to use sibling donors, possibly as a result of a shortage of donor eggs (Moorhead, 2009). The most up-to-date information comes from a survey of UK clinics conducted in April 2010 by the Human Fertilisation and Embryology Authority (HFEA, 2010). More than 40 per cent of

clinics reported receiving a request at least monthly for treatment using gametes donated by a family member, and more than three-quarters of clinics received such a request at least twice a year. The most frequent requests were for sister-to-sister or brother-to-brother donation, although other types such as father-to-son, daughter-to-mother and cousin-to-cousin donations were also occasionally requested. Half of the clinics reported carrying out treatment involving intra-familial donation at least four times per year.

Some UK clinics operate a pool egg donation system, offering recipients a choice of using their relative's egg (generally sisters) or that of an unknown donor from the pool. Significantly, up to half of recipients choose a stranger's egg from the pool. It would seem that in a situation of scarcity some may turn to their family as a source of available and affordable eggs, but, given the choice, may prefer to avoid the relational complications of using an intra-familial egg donor.

\section{Regulation and professional guidelines}

Intra-familial donation is permitted and practised in many countries. In countries that have regulated ARTs there is usually no distinction made between intra-family and other forms of donation and, therefore, what applies to these cases is the same as for donation in general. Some countries with no regulation have issued guidelines. The American Society for Reproductive Medicine (ASRM) produced an ethics committee report in 2003 on family members as gamete donors and surrogates. This guidance suggested the use of family members as donors or surrogates is generally ethically acceptable with brother-to-brother and sister-to-sister as the most acceptable. It found intergenerational donation was 'especially challenging' and donation involving consanguineous relations that give a 'strong impression of incest' should be prohibited. The report calls for special attention in terms of consent and counselling for this type of donation and the need for ART centres to have clear policies. While recognizing the ethical and psychological complexities, the overall tone of the report is positive. But it recommends that if any requests for intra-familial donation raise consistent concerns about potentially problematic family relationships or und ue pressure on the donor, the centre should have the right to refuse treatment.

In 2007 New Zealand's Advisory Committee on Assisted Reproductive Technology (ACART) issued 'Guidelines on Donation of Eggs or Sperm between Certain Family Members'. This document spells out the principles that should always be taken into account 
including the welfare of all involved, especially of the offspring. It states that the children should be made aware of their donor origins and be able to access information about the donor. It also specifies which requests will need to be reviewed by the National Ethics Committee on Assisted Reproductive Technology (ECART) when it comes to donation from family members. These include all requests other than: the donation of eggs by a sister or cousin of the recipient, when both are over the age of 20; donation of sperm by a brother or cousin of the recipient's husband, when both are 20 or older; donated eggs from the partner of the recipient woman and sperm by a brother or cousin of the recipient woman when both are over 20 - the age of majority at the time the guideline was developed (ACART, 2007).

Most recently, guidelines have been forthcoming from the European Society for Human Reproduction and Embryology's Task Force on Ethics and Law (ESHRE Task force on Ethics and Law, 2011). They found intra-family medically assisted reproduction to be a morally acceptable practice in some situations and under some conditions. They regard both combined and separate counselling of recipients and donors as crucial as it may contribute to both wellconsidered decision-making and risk reduction. But they argue that such treatments should be withheld in case of undue pressures on the donor or where there is a high risk of serious harm (psychosocial and/or genetic) for the possible child. While they see no a priori moral objection to intergenerational donation, they conclude that first-degree relative intergenerational donation needs special scrutiny in view of the increased risk of undermining autonomous choice. Cases involving third-degree consanguinity are found to be acceptable, in principle, while first- or second-degree consanguinity should be ruled out.

The ESHRE report also considers the issue of incest. They suggest that while most countries have laws and regulations forbidding consanguinity and incest which apply to sex, marriage and reproduction between closer than third-degree (genetic) relatives, such laws were written before the era of assisted reproduction and may therefore not explicitly rule out non-coital forms of reproduction between such relatives. However, they suggest that clinicians should conform to 'the spirit' of such regulation and rule out first- and second-degree consanguineous medically assisted reproduction. But as they point out, such cases are very unlikely to be proposed. They also consider cases where there is a semblance of incest and first- or second-degree consanguinity. One of their examples is of an adult daughter donating eggs to her mother whose new partner's sperm will be used to conceive the child.
As th is involves what they term reproduction between genetically unrelated adults, there is no consanguinity. They suggest the relationship is not incestuous because the daughter has no parent-child relationship with the mother's new partner. They conclude that unless serious moral objections can be found about these cases, where there is no coitus, no mixing of gametes of close relatives and no co-parenting of the gamete producers, such arrangements are acceptable (see also Pennings, 2001).

In this context the UK is unusual as it does have specific legislation governing assisted reproduction which has extended the prohibition of incest to intra-familial donation. As in other jurisdictions, UK law prohibits both marrying and sexual intercourse between close relatives linked by blood (first- and second-degree) and affinity (adoptive parents and children)(Sexual Offences Act, 2003; Marriage (Prohibited Degrees of Relationship) Act, 2004). The same list of forbidden relatives ${ }^{1}$ was applied in the situation of assisted reproduction where legislation (Human Fertilisation and Embryology Act, 1990, as amended) prevents those on the list from donating to each other if they plan to co-parent the children. The legislation embodies a notion of what Pennings (2001) has called 'intentional incest'. Donation to close relatives is not forbidden. So, for example, a case of a brother donating to an infertile sister who was using donor eggs would be law ful. However, a similar case treated in the USA, where again the sister used donated eggs, would have been illegal in the UK because the sister and brother who cohabited planned also to jointly parent the children.

Recently the Human Fertilisation and Embryology Authority (HFEA) has considered further extend ing the ban to rule out any mixing of gametes from close relatives. This and other issues concerning intra-familial donations are part of a current HFEA public consultation on donation pol icies.

Lists of forbidden relatives vary across jurisdictions and the UK list has changed over time. When the prohibitions embodied in cannon law were transferred into state legislation (The Marriage Act 1835) the list included the deceased wife's sister. Biblical doctrine saw marriage as creating 'one hesh' between husband and wife so in-laws were treated as blood relations and so included in the table of forbidden kindred and affinity. After a long period of parliamentary debates this prohibition was removed under the Deceased Wife's Sister Marriage Act of 1907 (Anderson, 1982). At an earlier time cousin marriage had been included in cannon law prohibitions. Such patterns of 'close marriage' became a very common and widespread pattern among the middle strata across Europe, North America and their colonies in the late eighteenth, and through the 'long' nineteenth centuries (Davidoff, 2006). 
A rather different approach to regulation has been taken in Japan. In 2003 a panel attached to the Ministry of Health's Science Council produced a set of guidelines on ART including the proposal to ban sibling donation. The arguments used to justify the ban were that such arrangements could unsettle family relationships or could lead to undue pressure for donation (Watts, 2003; Mayeda, 2006). These arguments are not particular to Japan. They have been raised by other regulators as issues of concern, but many other countries have chosen to allow a case-by-case assessment of each individual request by the health practitioner and clinic team or an ethics committee.

In New Zealand's programme for personal donors (donors found and chosen by recipients) there were some who chose brothers. All participants in the programme were united in their wish for a donor personally known to them, whose personality was familiar and who they liked as a person. But while some couples had chosen brothers as donors because the child's social father would be closer genetically to the child, others saw disadvantages in the family connection and preferred to use a friend instead. Those who preferred friends cited the possibility of feelings of obligation to donate to a family member, the 'closeness' of the situation and the complexity of relationships that would be created as reasons for their preference (Adair and Purdie, 1996).

\section{Reasons for intra-familial donation}

One of the reasons for seeking a gamete donor within the family can be the maintenance of a genetic link between both parents and the child (Adair and Purdie, 1996). Families who use an unknown (and unrelated) donor have children who are blood relatives of only one of the parents; many settle for this and such families are found to function very well (Daniels, 2005; Golombok et al., 2006; Grace and Daniels, 2007). However, some would prefer a genetic link with both parents (Pennings, 2001). This may be achieved, for example, by using a sister as an egg donor. In some cases it may be family membership that is important, rather than any genetic connection between donor and recipient; an example here would be having an egg donation from a sister-in-law.

The few studies that have investigated motivations for intra-familial donation have found that the wish for a genetic link between the donor and recipient, the fear of genetic material from an unknown donor and the child's physical resemblance to the parents were of importance (Baetens et al., 2000; Greenfeld and Klock, 2004; Winter and Daniluk, 2004), with the significance of the genetic link appearing to be more important for men than for women (Brewaeys et al., 1997). A practical reason for seeking intra-family donation is the acceleration of treatment. Generally there is a shortage of gamete donors and waiting periods for couples who wish to undertake fertility treatment can be long. Finding a family donor can speed up the process. There is a widely held view that as many countries move tow ard removing donor anonymity, fewer gamete donors will come forward and couples will be forced to look for alternatives. In countries where donors are receiving remuneration, particularly egg donors, reducing this expense may also be driving the quest to find a relative as a donor.

Relatives who volunteer to donate their gametes are primarily motivated by al truism and the wish to help members of the ir family ove rcome their infertility. This is a consistent finding in studies examining donor motivation (Purewal and van den Akker, 2009). A personal relationship with the recipient appears to play the most significant role; love for the sibling, in particular, is cited as the main motive by egg donors. The perceived importance of motherhood and coming from a large family were also reported as reasons to donate (Warren and Blood, 2003). In intergenerational donation, similarly there is a strong sense of helping the parent or child, and of providing a 'gift from the heart' (Lessor, 1993; Nikolettos et al., 2003; Winter and Daniluk, 2004).

Issues related to consanguinity and perceptions of incest have already been discussed, but aside from these questions, intra-family donation would still raise distinct ethical concerns more complex than using a known or unknown donor from outside the family. With intra-family donation, traditional family relations are altered to produce new patterns of blood, gestational and social relationships among family members, challenging those involved to work out some moral dilemmas and psychological uncertainties. These issues may affect the donor, the donor's own children, the parents and their offspring, as well as the wider family in a variety of ways. We will discuss the key issues arising in intra-family donation for the various parties involved and present some new data from the first longitudinal study to examine families created by intra-family donation (Jadva et al., 2011).

\section{The donor relative}

Intra-family donors tend to be motivated by the need to help their relatives create a family and alleviate their suffering from infertility. In an ideal situation this is an altruistic gesture by the donor who is fully aware of the physical and psychosocial implications of donation. $\mathrm{He}$ or she either initiates the process or is responsive to a request from the 
recipients. There is often a concern that emotional pressure may be put on the relative to donate. This pressure may be external, caused by other family members or internal, driven by feelings of obligation to help the relative. This issue has been discussed in detail in the context of live organ donation and the analysis can also be applied here (Crouch and Elliott, 1999). Emotional pressure could lead to coercion and so restrict the would-be donor's autonomy. While this can occur, it is impossible to make blanket statements, and of course this can happen with any known donor, not only family members. The individual's relationship to the recipient, to other family members and his or her perception of the family as a whole, including religious views, will influence the decision-making process and subsequently the extent to which the donor can make a free decision. Some commentators have suggested that it may be impossible to make a free decision, for example when parents request a child's involvement (i.e. the son to donate sperm to his father), given the role of parental authority and possible issues of dependence, financial or otherwise (Sureau and Shen field, 1995). On the other hand, Finch and Mason (1993) have shown that rather than being viewed as an obligation, giving assistance to family members is usually carefully negotiated and often has advantages for the donor as well as the recipient. A sister who donates her eggs, for example, may not only enhance feelings of family solidarity but also her own identity as a caring sister: an altruistic gift relationship of the kind discussed by Titmuss (1970). Finch and Mason have also shown that family members may not wish to be beholden to each other so it would not necessarily be in the best interests of those in need of gametes to put undue pressure on relatives who might donate.

The measures that are typically taken to protect the donor's autonomy are the informed consent process and counselling. Both are sine qua non in all donations and certainly in intra-family donation, but still there are questions to be asked. A consent process operates on the basis of personal autonomy. The individual is presumed to be capable of making a free and rational decision after having received the relevant information. The consent process cannot, however, ensure that the donor has reached a 'free' decision un in fluenced by the relationship with his or her relatives. In thinking about intra-family donation, the concept of 'relational autonomy' might be more useful. This concept acknowledges the importance of personal autonomy but also how th is is influenced and shaped by various relationships and the broader social context (Mullen, 2001). Therefore, it provides a richer understanding of what a 'free choice' actually is and all of the factors that can lead an individual to consider a particular action as free (MacLeon and
Sherwin, 2000). In practical terms, recognition of relational autonomy can lead to better processes for recruitment of intra-family donors (how the options are presented) and better consent processes (how the risks and benefits are discussed) while it can further inform the counselling process. In live organ donation it is usual practice to in terview the would-be donor and the recipient independently. If the donor is found to be at all reluctant to donate, 'medical reasons' are found which make the donor unsuitable.

A specific question about the counselling process is the extent to which it can prepare the donor for what the future holds. The donor (if the treatment is successful) will be the genetic parent of the offspring but with in the family would have a different social role. So, for example, with sisters the donor will be aunt to the child and her own children will be half-siblings of the donor child. While the donor may see herself as a rather special aunt, her own children may remain unaware of their new half-siblings and the mother may prefer to emphasize her sisterhood with the donor and her motherhood of the child she has carried (Lessor, 1993). As these half-siblings may resemble one another, there will always be a risk that they or others may come to realise the true relationship between them, and it is not known how those who become aw are that they are half-siblings rather than cousins will feel about their family circumstances. In brother-to-sister donation where the sister uses donated eggs, the social mother would be the gestational mother but without a genetic relationship to the child, and the genetic father would be the social uncle, while some cousins would be half-siblings. With daughter-to-mother donation, the genetic mother would be the child's social sibling and the social mother would be the child's genetic grandmother. It is maybe difficult to imagine at the time of a donation how one might feel in the future about the offspring with whom (unlike in unknown donation) one would have a social relationship and under circumstances that cannot be known at the time of the donation (for example, the donor might end up not having children of their own).

Furthermore, the donor will inevitably be involved in any failed attempts at conception or in conceptions of unhealthy children. Failed cycles have been reported as having a major psychological impact on donors (Purewal and van Akker, 2009). The donor can suffer through treatment failure even though he or she is not the patient. Similarly, if the child suffers from a genetic disease or disability, there is a risk that the donor might feel at least partially responsible. The potential for emotional harm for the donor should not be underestimated. In unknown donation the donor would most likely not know the outcome of his or her donation and therefore this type of harm would be avoided. 
Altruistic donation usually receives social recognition, and such recognition may contribute to the donor's satisfaction and well-being. Intra-family donation, however, may completely lack this particular element or may even create an adverse reaction (Marshall, 2002). Some intra-family donations are not viewed positively as they appear to resemble incest (even if they do not) or they are kept a close secret so there is no opportunity for recognition or appreciation.

There are few studies addressing these issues and those that do tend to have relatively small samples. Findings about the post-donation experience of intra-family donors are therefore not conclusive and appear somewhat contradictory (Winter and Daniluk, 2004). In one recent follow-up study of oocyte donors who donated to known recipients including family members, most donors were satisfied with the physical and emotional implications of their donation and only a small minority reported difficulties and distress when seeing the child (Yee et al., 2007).

\section{The family}

An issue that extends beyond the donor to the family network is how family relationships might be affected by the donation. The empirical data show diverse outcomes. In an older study, 75 per cent of known semen donors said that their relationship with the recipients had become closer while the remainder felt that their relationship had deteriorated (Adair and Purdie, 1996). Other studies have reported a strengthening of relationships between the donor and recipients (W inter and Daniluk, 2004). An invest igation from the Netherlands of known oocyte donation reported that 88 per cent of the recipients described their relationship with the donor as close and friendly or fairly close and friendly; only a small minority seemed to have problems (Van Berkel et al., 2007). However, we should note that these studies concern known donors, most of whom were not family members. The two issues that may profoundly affect family relationships are boundaries between the donor and recipients, and secrecy. Both ra ise ethical conund rums.

At th is point we will describe some of the results from the ongoing study being carried out by one of the authors and her colleagues. As part of a longitudinal investigation of a representative sample of Brit ish families created by gamete donation (Golombok et al., 2004, 2005, 2006 and 2011), 9 families were identified where the child had been conceived using the egg of a family member. Of these egg donors 6 were sisters of the mother and 3 were sisters-in-law, of whom 1 was the wife of the mother's brother, 1 was the wife of the father's brother and 1 was the female partner of the father's sister (Jadva et al., 2011). Interviews about family relationships were carried out when the children were 1 , 3 and 7 years old. Most of the families were middle class and half the group came from black British, Asian or other ethnic minority groups. This is a surprisingly high proportion and while the numbers are very small, it at least ra ises the question of whether sister/sister-in-law donation may be particularly favoured in some cultures. Whereas having a donor from within the family, and the genetic or familial links that th is provides, were seen as an advantage by some, for others there were more practical considerations in view of the long waiting list for an anonymous egg donor.

In most families it had been agreed that the donor would be the child's aunt and nothing more but in two families it was decided that the donor would have a special role such as a godmother. There was no evidence whatsoever of donors wishing to adopt a mothering role, a situation that parallels that of surrogate mothers who do not view the child they carry for another couple as their own (Jadva et al., 2003). One mother whose egg donor was her sister commented: 'She's very, um, I don't know what the word is really, not detached, but just very much, you know, stepped back ... If she sends a card she always sends it "to my nephew", you know, that kind of thing.' Another mother said: 'She's my sister, so she is my daughter's auntie, and she is very much her auntie, and that is her role.'

The mothers themselves appeared secure in their role as mother of the child and many commented that they rarely thought about the relative being the child's genetic parent. However, some mothers were concerned to ensure that the child viewed them as their mother. For one mother this was given as a reason for not telling her child about the egg donor: 'I suppose I just wouldn't want her to be conf used about who she was and who her mother was.' Another mother who had been open with her child said: 'We're always very clear that she's come from mummy that she grew in mummy's tummy so she knows that that connection is there. I don't want her to think that my sister is her mummy.'

In all but one of the families the mother and child were in regular contact with the donor, although over time this reduced somewhat. At age 7,2 (of 5 participating at that point) were in contact at least once a month, 2 less frequently and 1 was in telephone contact only. The children tended to have less frequent contact than the mother. The mothers continued to rate their own and the child's relationship with the donor as harmonious with the exception of one mother who reported some dissatisfaction and coldness but no major conflict or hostility. All 
of the mothers felt that the donor's involvement with the child was positive apart from one mother who felt ambivalent.

At the time of the child's first birthday, 6 of the mothers planned to tell the child about their donor origins, with the remaining 3 having decided against telling. However, by the time the child was 7 years old, only one set of parents had actually done so. Of the 4 remaining families who were interviewed at age 7,3 still planned to tell, one at age 7 , one at age 10 and one at age 18. These mothers had not yet disclosed this information as they felt that their child was too young to understand. Previous research on children conceived by anonymous gamete donation has shown that if parents do not tell their child about their genetic origins by early school age, they tend not to do so (Golombok et al., 2002a, 2002b). Thus it seems likely that almost all of these children conceived by intra-family donation will grow up unaware that a person they know as their aunt is actually their genetic mother.

Although most mothers had not disclosed the donor conception to their child, many had told other family members including paren ts, their partner's parents, their siblings and their partner's siblings They had not, however, always told the full story. Some had mentioned having fertility treatment but not the use of a donated egg, and some had been open about the donated egg but not about the identity of the donor. In some cases, the egg donor's family or the egg donor's partner's family were not aware of the egg donation, that is that a child born into the family was related to them in a way that differed from their understanding of their relationship to that child.

If family members are aware of the donation but the child is not, the child may find out by accident or inadvertently due to resemblance. One mother expressed her anxiety about the similarity in appearance between her child and the donor's children and talked about being taun ted by her mother-in-law who had not been told: 'Yesterday I went to my mother-in-law's and she looked at her and said she looks like ... she looks like your nephew ... it's hard to swallow.' Another mother was concerned about her child and her sister's [the donor's] child working it out for themselves because they looked alike: 'As babies my sister's [donor's] daughter and my daughter looked very, very alike, you know they could have been twins ... If ever a situation came up when perhaps one of them clicked on to something or just felt they looked alike we would tell them straight away ... because then you've got a situation where cousins aren't really cousins, they're brothers and sisters and it gets complicated.
The one family who had been open with their child from the start, where the donor was the mother's sister, did not have any reg rets, in spite of the child informing her entire school: "There was a lovely moment when they had an assembly where everyone was talking about how they were special and what's special about you and my daughter's hand sho up and I thought to myself what is she going to say, she's never put her hand up and she isn't usually one to volunteer, so up shoots her hand and the teacher said why are you special and she said I'm special because I come from my mummy's sister's egg and the teacher said oh did you, that does make you special!'

Although th is sample is small, it was drawn from a larger, representative sample of families with a child conceived by egg donation. An advantage of the study is that the families were recruited while the children were still in infancy, thus avoiding the potential biases associated with opting in or out of the investigation once the child had formed a relationship with the donor or had acquired the capacity to understand the true nature of this relationship. Moreover, the families were followed up until the child entered middle childhood, that is beyond the age at which children develop an understanding of the meaning of biological relationships (e.g. Solomon et al., 1996; Brodzinsky and Pinderhughes, 2002; Williams and Smith, 2010).

The concern that intra-family donation would have an adverse impact on family relationships appears to be unfounded. Although the don ors themselves were not in terviewed so no conclusions can be drawn about their feelings or experiences, for example, about whether they fel under pressure to donate or whether they are satisfied with their level of involvement with the child, data obtained from mothers suggests that egg donation by a sister or sister-in-law did not have a detrimental effect on the relationship between the donor and either the parents or the child. Without exception, the two sets of adults clearly maintained their social roles within the family as mother and father, and aunt and uncle, respectively, and there was no evidence that either of the parties involved wanted it any other way.

But it is noteworthy that in only one family had the child been told about their genetic orig ins by the time they reached 7 years old. This was in spite of the greater risk that these children would find out by accident about the circumstances of their birth than child ren conceived by anonymous gamete donation. In addition to the usual concerns experienced by parents regarding the disclosure of donor conception to their child, such as the fear that this would distress the child or that the child would love the non-genetic parent less (Cook et al., 1995; Golombok et al., 2002a, 2002b), the reluctance of parents whose child 
was conceived using the egg of a relative to be open with their child stems from the desire to avoid the unknowable complications that could potentially arise within the extended family.

Tension may rise when the recipient couple and the donor do not agree on the boundaries they wish to draw. Should the donor be actively involved in the child's life? How involved should he or she be? Should he or she have a say in parenting decisions? In a traditional family, an aunt or uncle or grandparent may be significantly involved, or not, in the life of the couple and their children. Should a social uncle or aunt who is also the genetic father or mother of the child have more rights to involvement in the child's life? This question can be asked in moral, legal and psychological terms. The answers will differ. From the legal point of view the answer is straightforward. In most situations in many jurisdictions parental rights and duties are transferred from the donor to the recipient parents. Morally speaking, it is generally accepted that a donor does not have any parental obligations to the of fspring nor any parental rights because he or she has made a free decision to transfer such rights to other people (Bayne, 2003; Fuscaldo, 2006) and this remains the case if the donor is a relative. However, the opposite has been argued, namely, that gamete donors have parental responsibilities because such a responsibility is by default not transferable (Weinberg, 2008). In theory, at least, a known donor could claim rights and duties; indeed, disputes may a rise about the extent to which a known donor may be involved in a child's life or, in some situations in some jurisdictions, may be able to claim parental rights and duties. With intra-familial donation the donor will already have a kindred role in the child's life. A donor may bond with the child and may feel to some extent that the child is their 'own', especially if there is a resemblance. In the study by Winter and Daniluk (2004), the oocyte donors who donated to their sister reported their anxiety at first meeting their niece or nephew arising from the fear that the child would resemble them too much, or that they would experience maternal feelings. All three women in this study, however, seemed to have no boundary conf usion and were able to maintain a clear line between their roles as donor and aunt. The Dutch study by Van Berkel et al. (2007) found that contact with the donor remained good and frequent af ter the birth of the child, and half of the recipients saw their donor daily or once a week. Only a minority of parents reported problems in their relationship with the donor because of too much interference by the donor in the child's life.

Gamete recipients might have difficulties accepting a very involved 'uncle' or 'aunt'. They might find it particularly difficult to deal with such an issue in the context of the gratitude they would inevitably feel to someone who gave them a 'gift from the heart'. Gratitude towards the donor and a sense of reciprocity, allowing the donor to be involved in the child's life, may, however, create tension and difficult relationships. Such tension might spill over to other family members who may or may not know about the donation depending on who has been told. Conversely, one could argue that the close involvement of the donor may actually be welcome and enhance the family network, bringing family members much closer to each other. As yet, we know very little about how such relationships play out in different families. There is a need for further longitudinal data on how such families function, the specific issues that they face and how they resolve them in both the short and long term.

Secrecy is another issue of relevance to intra-family donation. As donors are family members who may have regular contact with the recipients, it may be more difficult for families who wish to do so to keep the donation secret. The evidence here is again inconclusive. Some early studies of intra-family donation found that the majority of donors had not informed other members of the family (Purewal and van den Akker, 2009). Others have reported a tendency towards openness (Yee et al., 2007; Van Berkel et al., 2007). A complicating factor is that the donor and the recipients may have different values, views and beliefs regarding this issue. Although secrecy about genetic parentage has increasingly been viewed as undesirable, with parents who do not disclose donor conception to their children considered to be self-serving, Smart (2009) points out that secrets may be felt to be necessary for the preservation of family relationships. This may be particularly likely in the case of intra-family donation as not only a re parent-child relationships perceived to be at risk but also relationships between the nuclear family and wider kin. As we described earlier, only one of those in the longitudinal study had told their child of their donor origins by age 7 .

\section{The offspring}

The welfare of the child is a central theme in most debates about ARTs. This dictates that the child's best interests should always be taken into account and that treatment should not be undertaken if it is probable that the child may suffer physical or psychological harm. In intra-family donation the welfare of the potential child remains of prime concern. While the probability of physical risk is not higher than in donation in general (assuming consanguinity is avoided), concerns focus on the probability of psychological and social harm. Of particular relevance is the issue of disclosure to the child, and the impact of information about 
the donor conception on the child's psychological well-being. Studies have shown that in families created with the help of a donor, parentchild relationships have not been negatively affected following disclosure if the child is told by the parents early in childhood (Rumball and Adair, 1999; MacDougal, 2007; Jadva et al., 2009) (see Appleby, Blake and Freeman, Chapter 13). In addition, studies investigating donor of fspring's perceptions of family functioning in relation to disclosure showed that parents' disclosing together was predictive of more positive family functioning (Berger and Paul, 2008).

Despite the advice from counsellors and other health care practitioners to tell children, most parents of children conceived by donor gametes do not do so. Research conducted in the UK, for example, has found that in spite of parents' intention to be open with children about their donor conception, less than half actually disclose (Golombok et al., 2002a, 2002b; Golombok et al., 2011). The reasons parents give for their decision not to tell are to protect the child and maintain family relationships (Cook et al., 1995; Murray and Golombok, 2003). The common argument for disclosure is the right of the child to know about their donor conception and to prevent children learning about this from someone other than the parents. With known donation, most studies have reported the reluctance of parents to disclose this information to the child. The need for secrecy in order to protect the family as a whole has been suggested as a reason for non-disclosure of intra-family donation but the studies are not conclusive regarding the role this actually plays (Purewal and van den Akker, 2009).

Disclosure in intra-family donation may have far-reaching implications and certainly has the potential to alter the dynamics of relationships in the extended family. The situation whereby family members are aware of the donor conception but the child is not is similar to that of many families with a child conceived using an anonymous donor, thus creating a risk that unintentionally the child will find out about their origins. However, intra-family donation brings additional layers of complexity. It may be more distressing to a child to discover that their donor is a family member - to discover not only that they lack a biological link with one of their parents but also that an aunt, uncle, grandmother or grandfather is not exactly who they thought they were. Also, they could inadvertently discover the truth about their origins through their resemblance to other family members. A unique aspect of secrecy about intra-family donation that does not apply to anonymous gamete donation is that the children are unaware that the donor's children, whom they will know, are their (genetic) half-siblings. In the case of sister-to-sister donation, for example, their cousins are actually their (genetic) half-brothers and half-sisters.

The question here is whether offspring are better of $f$ knowing about the involvement of a relative in their conception or not, given the unknown consequences, since so many other people will inevitably be affected. Until information can be obtained directly from the offspring of intra-family donation, predictions about their thoughts and feelings about being conceived using the gametes of a family member remain purely speculative. It might be expected that their reaction to this information would depend on the quality of their relationship with their parents, and also with the family member to whom they find themselves more closely related than previously thought. Finding out that you are the biological daughter of a much-loved aunt may provoke a rather a different response than the discovery that you are the biological daughter of a disapproving one. Good relationships with both the social mother and the new-found genetic mother may cause the child to feel more secure; bad relationships with the two 'mothers' may lead to double psychological trouble. On a more positive note, in contrast to the offspring of anonymous donors, there is no need to search for the donor and donor siblings in the quest for information about genetic relatives. Not only do children born from the gametes of a family member know who their donor relatives are but they also know what they are like.

Research on children conceived through anonymous gamete donation indicates that the earlier they are told about their conception, the more easily they accept this information and incorporate it into their sense of self. Those who find out in adolescence or in adulthood are more likely to feel shocked, distressed and deceived (Turner and Coyle, 2000; Jadva et al., 2009). It is conceivable that the additional challenges presented by intra-family donation may exacerbate the more negative feelings of those who learn of their origins later in life. They may feel deceived not just by their parents but by their family as a whole.

If we accept that truth-telling has a higher moral value and that secrecy has a deleterious effect on family functioning, then disclosure would be the recommended approach. The words of Baroness Mary Warnock about disclosure in donation hold true in intra-family donation as well: 'I cannot argue that children who are told of their origins .. are necessarily happier or better off in any way that can be estimated. But I do believe that if they are not told they are being wrongly treated' 
(1987: 151). What makes the issue of disclosure dif ficult to resolve from an ethical perspective is that it automatically involves the donor, the recipient, the partner of the recipient and the child as well as other family members. If they do not all share the same beliefs and wishes about disclosure, a conflict is created between their respective individual rights. The principles of individual autonomy, beneficence and fairness are simultaneously at stake and may be at odds. It is not clear that these principles are in any certain hierarchy and it is therefore challenging to determine how they may coexist and what compromises need to be made.

A practical arrangement that may prevent future conflict is where recipients and donors decide prior to the donation about the issue of the disclosure. In the study by Van Berkel, about 53 per cent of the recipients and donors had made an agreement before the egg donation about how to deal with disclosure to the child. The agreements included whether the parents would disclose together with the donor, and at what point (Van Berkel et al., 2007). This is merely a practical arrangement that may help prevent potential conflict, but it does not necessarily guarantee the well-being of the child, nor does it resolve the ethical dilemmas that may arise.

\section{Conclusions}

Intra-family donation is a complex arrangement and there is still much uncertainty about its ethical acceptability. Although it may be an appropriate solution for some families, it may be detrimental for others. The principles of autonomy, relational autonomy and non-maleficence are at stake and may conflict. While such principles may be competing in the use of other medical interventions, at least a favourable risk/benefit ratio for the patient is the minimum required standard in order to accept a procedure. However, it is problematic to use the risk/benefit approach here as there is not only one person/patient but at least three (plus the extended family) and also because we cannot accurately estimate the risk and benefit as the psychological risks for all involved are unknøwn.

Further empirical data will help us make a better assessment of the risks and benefits involved and therefore form more robust arguments. It would seem to be premature to try to prohibit intra-family donation based on the speculation that it might be harmful. Given our current knowledge and in light of the ethical issues involved, a caref ul case-bycase analysis of each request may be the most reasonable approach.

\section{REFERENCES}

Adair, V. and Purdie, A. (1996). 'Donor insemination programmes with personal donors: issues of secrecy'. Human Reproduction, 11, 2558 ‥63.

Advisory Committee on Assisted Reproductive Technology (ACART) (2007). Guidelines on Donation of Eggs or Sperm between Certain Family Members. New Zealand.

American Society of Reproductive Medicine (ASRM) Ethics Committee Report (2003). 'Family members as gamete donors and surrogates'. Fertility and Sterility, 80, 1124-30.

Anderson, N. F. (1982). "The "marriage with a Deceased Wife's Sister Bill" controversy: incest anxiety and the defence of family purity in Victorian England'. Fournal of British Studies, 21, 67-86.

Baetens, P., Devroev, P., Camus, M., Van Steirteghem, A., et al. (2000). 'Counselling couples and donors for oocyte donation: the decision to use either known or anonymous oocytes'. Human Reproduction, 15, $476-84$.

Bayne, T. (2003). 'Gamete donation and parental responsibility'. Fournal of Applied Philosophy, 20, 77-87.

Berger, R. and Paul, M. (2008). 'Family secrets and family functioning: the case of donor assistance'. Family Process, 47, 553-66.

Brewaeys, A., Golombok, S., Naaktgeboren, N., de Bruyn, J. K., et al. (1997). 'Donor insemination: Dutch parents' opinions about confidentiality and donor anonymity and the emotional adjustment of their children'. Human Reproduction, 12, 1591 $\cdots$.

Brodzinsky, D. and Pinderhughes, E. (2002). 'Parenting and Child Development in Adoptive Families', in M. H. Bornstein (ed.), Handbook of Parenting, vol. 1. Mahwah: Lawrence Erlbaum Associates, pp. 279-312.

Cook, R., Golombok, S., Bish, A. and Murray, C. (1995). 'Keeping secrets: A study of parental attitudes toward telling about donor insemination'. American fournal of Orthopsychiatry, 65, 549-59.

Crouch, R. and Elliott, C. (1999). 'Moral agency and the family: the case of living related organ transplantation'. Cambridge Quarterly of Healthcare Ethics, 8, 275-87.

Daniels, K. (2005). 'Is blood really thicker than water' Assisted reproduction and its impact on our thinking about family'. Fourrial of Psychosomatic Obstetrics and Gynaecology, 26, 265-70.

Davidoff, L. (2006). "Close Marriage" in the Nineteenth and Twentieth Century Middle Strata', in F. Ebtehaj, B. Lindley and M. Richards (eds.), Kinship Matters. Oxford: Hart Publishing.

ESHRE Task Force on Ethics and Law (2011). 'Intra-familial medically assisted reproduction'. Human Reproduction, 26, 504-9.

Finch, J. and Mason, J. (1993). Negotiating Family Responsibilities. London: Routledge.

Fuscaldo, G. (2006). 'Genetic ties: are they morally binding?' Bioethics, 20, $64-76$ 
Golombok, S., Brewaeys, A., Giavazzi, M. T., Guerra, D., et al. (2002a). 'The European study of assisted reproduction families: the transition to adolescence'. Human Reproduction, 17, 830-40

Golombok, S., MacCallum, F., Goodman, E. and Rutter, M. (2002b). 'Families with children conceived by donor insemination: A follow-up at age 12'. Child Development, 73, 952-68.

Golombok, S., Lycett, E., MacCallum, F., Jadva, V., et al. (2004). 'Parenting infants conceived by gamete donation'. Foumal of Family Psychology, 18, $443-52$.

Golombok, S., Jadva, V., Lycett, E., Murray, C., et al. (2005). 'Families created by gamete donation: follow-up at age 2'. Human Reproduction, 20, 286-93.

Golombok, S., Murray, C., Jadva, V., Lycett, E., et al. (2006). 'Non-genetic and non-gestational parenthood: consequences for parent-child relationships and the psychological well-being of mothers, fathers and children at age 3'. Human Reproduction, 21, 1918-24.

Golombok, S., Readings, J., Blake, L., Casey, P., Mellish, L., Marks, A. and Jadva, V. (2011). 'Children conceived by gamete donation: the impact of openness about donor conception on psychological adjustment and parent-child relationships at age 7'. Foumal of Family Psychology, 25, $230-9$.

Grace, V. M. and Daniels, K. R. (2007). 'The (ir)relevance of genetics: engendering parallel worlds of procreation and reproduction'. Sociolosy of Health and Illness, 29, 692-710.

Greenfeld, D. and Klock, S. (2004). 'Disclosure decisions among known and anonymous oocyte donation recipients'. Fertility and Sterility, 81, $1565 \cdots 71$.

Human Fertilisation and Embryology Authority (HFEA) (2010). Donation Revierv: Update and Early Options. Paper number 561. London: HFEA

Jadva, V., Murray, C., Lycett, E., MacCallum, F., et al. (2003). 'Surrogacy: the experiences of surrogate mothers'. Human Reproduction, 18, 2196-204

Jadva, V., Freeman, T., Kramer, W., and Golombok, S. (2009). 'The experiences of adolescents and adults conceived by sperm donation: comparisons by age of disclosure and family type'. Human Reproduction, 24, 1909-19.

Jadva, V., Blake, L., Casey, P., Readings, J., Blake, L. and Golombok, S. (2011). 'A longitudinal study of recipients' views and experiences of intra-family egg donation'. Human Reproduction, 26, 2777-82.

Lessor, R. (1993). 'All in the family: social processes in ovarian egg donation between sisters'. Sociology of Health and Illness, 15, 393-413.

Lessor, R., Reitz, K., Balmaceda, J., and Asch, R. (1990). 'A survey of public attitudes towards egg donation between sisters'. Human Reproduction, 5 , 889-92.

MacDougal, K. (2007). 'Strategies for disclosure: how parents approach telling their children that they were conceived with donor gametes'. Fertility and Sterility, 87, 524-33.

MacLeon, C. and Sherwin, S. (2000). 'Relational autonomy, self-trust in health care for patients who are oppressed', in C. Mackenzie and N. Stol-Jar (eds.), Relational Autonomy: Feminist Perspectives on Autonomy, Agency and the Social Self. New York: Oxford University Press.

Marshall, L. (2002). 'Ethical and legal issues in the use of related donors for therapeutic insemination'. Crologic Clinics of North America, 29, 855-61.

Mayeda, M. (2006). 'Present state of reproductive medicine in Japan - ethical issues with a focus on those seen in court cases'. Biomed Central Medical Ethics, 7, 1-16.

Moorhead, J. (2009). 'My sister's egg gave me a baby'. The Guardian. 22 August.

Mullen, M. (2001). 'What oocyte donors aren't told?' American fournal of Bioethics, 4, 1-2.

Murray. C. and Golombok, S. (2003). 'To tell or not to tell: the decision-making process of egg donation parents'. Human Fertility, 6, 89-.95.

Nikolettos, N., Assimakopoulos, B. and Hatzissabas, I. (2003). 'Intrafamilial sperm donation: ethical questions and concerns'. Human Reproduction, 18, 933-6.

Pennings, G. (2001). 'Incest, gamete donation by siblings and the importance of the genetic link'. Reproductive Bionedicine Online, 4, 13-15.

Purewal, S. and van den Akker, O. (2009). 'Systematic review of oocyte donation: investigating attitudes, motivations and experiences'. Human Reproduction Update, 15, 499-515.

Rumball, A. and Adair, V. (1999). 'Telling the story: parents' scripts for donor offspring'. Human Reproduction, 14, 1392-9.

Sauer, H. (1988). 'Survey of attitudes regarding the use of siblings for gamete donation'. Fertility and Sterility, 49, 721-2.

Smart, C. (2009). 'Family secrets: law and understandings of openness in everyday relationships'. Foumal of Social Policy, 38, 551-67.

Solomon, G., Johnson, S., Zaitchik, D. and Carey, S. (1996). 'Like father, like son: young children's understanding of how and why offspring resemble their parents'. Child Development, 67, 151-71.

Sureau, C. and Shenfield, F. (1995). 'Should gamete donation between family members be restricted?: Oocyte donation by a daughter'. Human Reproduction, 10, 1334.

Titmuss, R. M. (1970). The Gift Relationship: From Human Blood to Social Policy. Harmondsworth: Pelican.

Turner, A. J. and Coyle, A. (2000). 'What does it mean to be a donor offspring? The identity experiences of adults conceived by donor insemination and the implications for counselling and therapy'. Human Reproduction, 15, 2041-51.

Van Berkel, D., Candid•, A. and Pijffers, W. H. (2007). 'Becoming a mother by non-anonymous egg donation: secrecy and the relationship between egg recipient, egg donor and egg donation child'. Fournal of Psychosomatic Obstetrics and Genecology, 28, 97-104.

Warnock, M. (1987). 'The good of the child'. Bioethics, 2, 141-55.

Warren, N. and Blood, J. (2003). 'Who donates? Why donate? An exploration of the characteristics and motivations of known egg donors: the Victoria Australia experience'. Foumal of Fertility and Counselling, 10, 2-24. 
Watts, J. (2003). 'Panel advises against egg and sperm donations from siblings'. The Lancet, 361, 1532.

Weinberg, R. (2008). 'The moral responsibility of sperm donation'. Bivethics, $22,166-78$

Williams, J. and Smith, L. (2010). 'Concept of kinship relations and inheritance in childhood and adolescence'. British fournal of Developmental Psychology, 28, 523-46.

Winter, A. and Daniluk, J. A. (2004). 'A gift from the heart: the experiences of women whose egg donations helped their sisters become mothers'. Foumal of Counseling and Development, 82, 483-95.

Yee, S., Hitkari, J. and Greenblatt, E. (2007). 'A follow-up study of women who donated oocytes to known recipient couples for altruistic reasons' Human Reproduction, 22, 2040- -50.

\section{LEGISLATION}

Deceased Wife's Sister Marriage Act 1907

Human Fertilisation and Embryology Act 1990, as amended

Marriage (Prohibited Degrees of Relationship) Act 2004

Sexual Offiences Act 2003

The Marriage Act 1835

\section{ARTs and the single parent}

\section{Susanna Graham and Andrea Braverman}

\section{What are single parents by choice?}

Single parents by choice (SPCs) are single men (single fathers by choice), or women (single mothers by choice), who actively choose to parent a child without a partner. The term single mother by choice (SMC) has been used to describe a distinct group of women who differ in a number of ways from mothers who either conceive accidently or become single after separation or divorce (Chan et al., 1998; Mannis, 1999; Murray and Golombok, 2005a, 2005b). They are of ten older women, predominantly heterosexual, in their thirties and forties, well educated and financially independent (Murray and Golombok, 2005a, 2005b; Hertz, 2006; Jadva et al., 2009a). There is currently a dearth of academic literature concerning single fathers by choice (SFCs) and little is known about such men or the children they raise.

\section{Routes to single parenthood by choice}

An SPC decides to have a child knowing that they will parent that child, at least initially, without a partner. This can be achieved via various routes and does not necessarily have to incorporate the use of Assisted Reproductive Technologies (ARTs). A woman could embark upon single motherhood by choice through sexual intercourse, donor insemination (DI) at a clinic, self-insemination with a known or anonymous donor, as well as through adoption or fostering (Bock, 2000; Hertz, 2006). Research has shown that different women choose different methods depending upon their circumstances, the options available to them and their beliefs about the morality of different methods. For example, some women may feel it is wrong to deceive a man by purposefully getting pregnant through a sexual encounter (Bock, 2000; Murray and Golombok, 2005a) while others feel that adoption is a morally superior route to single motherhood (Mannis, 